\title{
Dear President Macron; an Ordinary People Get Anger to You (But I know you are Not Meant to Be)
}

\author{
Thobias Sarbunan \\ IAKN Ambon, Indonesia \\ Email: t.sarbunan@iaknambon.ac.id
}

\section{ARTICLE INFO}

Date received : 16 October 2020

Revision date : 04 November 2020

Date received : 16 November 2020

\section{Keywords:}

The President Speech

Politic Discourse

Language and Politic

Rhetoric

\begin{abstract}
Emanuel Macron was excavated the anger from thousands of people around the world, that society in fact was Muslim people. Therefore, number of protest escalated in many countries including Indonesia, as the biggest Muslim country in the world. I as personal, also stand in scientific circle, in fact was indeed concerned to that chaos affected by politic speech. Therefore, in short, this paper conducted to educate the widespread society, 'who stand-out of politic activity also the system', to bridge that society knowledge toward politic speech and related issue around politic knowledge. By the end, I see that politic knowledge was concrete and systematic, that not think before. Moreover, to react in this issue, the matter of politic speech, even the discourse that related to language-politic, how politician act through rhetorician movement, all of that knowledge must be learned and highlight to the broad people, that in purpose to prevent undesired act such violence or riot, which harmfully to all of us, even in systematic impact.
\end{abstract}

\section{INTRODUCTION}

Politic and language were the elements interchangeable and determined to the wide range of life. According to (Medriano Jr \& De Vera, 2020) in practical issue of politic affair, "on the concept of rhetoric and rhetoric strategies, scholars agree on a common concept of "rhetoric" which is ascribed as the art of persuasion, or the study of the art of persuasion, and an individual act of persuasion. Therefore, three modes of persuasion, also determines to the type of rhetoric strategies. The instrument serves as a theoretical basis for the construction of one of the instruments. While talked about the speech itself, not only its tendency to the communication knowledge, but also language, speech related to the theory of speech act. In speech act, speech acknowledged as basic units of linguistic interaction. In detail of speech act component, the locutionary act is the act of saying something, illocutionary act is the act performed in saying something, while the perlocutionary act is the act performed by saying something, the effect the utterance has on the psychological state of the hearer".

(Ali \& Davis-Floyd, 2020) agrees and said that "human beings begin by acknowledging that language plays an essential role in our lives, including expressing our experiences, transmitting our emotions, and affecting others. It has many and multidimensional roles. Language allows us to convey our perceptions of the phenomenon as well as to shape us. The vocabulary will unify humans with or isolate from a phenomena. After decoding the encoded meanings of words, we behave and respond. These meanings emerge from the memory of culture".

Again, in (Aistrope, 2020) stressing point, "It is commonly understood that mainstream culture occurs with and influences our perception of world affairs. The way vocabulary and images from fiction, drama, film, television and other cultural development sites find their way into political 
discourses on geopolitics, crime, immigration, imperialism and weapons control have been illustrated in various reports, to name a few. In comparison, global events, especially foreign crises, offer rich topics across mediums and genres for popular culture. The theory of intertextuality, which highlights the way in which the meaning and authority of any text is established by drawing on or positioning against other texts from the surrounding culture, has often understood this interchange".

(Abulof, 2020) from the political view, this scholar argued that, "the right of peoples to selfdetermination lies at the heart of the modern quest for statehood. This century-old principle warrants a world of true nation-states, where national boundaries make state borders, not the other way around. I argue, however, that the concept of 'selfdetermination' has been effectively [ab/used] to foil, rather than foster, its original goal, and explain why and how this paradox transpired. In theory, selfdetermination is a potent 'speech-act': by uttering, en masse, their demand for self-determination, people(s) can change their politics, even create new states. In practice, however, powerful actors have tried to tame self-determination - by appropriating this right from the peoples, and delimiting its applicability to oppressed, non-ethnic communities and to sub-state solutions".

More specifically, "speech style has been treated as 'attention paid to speech,' which means that style shifting along the [in-formality] axis is the result of the number of speakers paying attention to the monitoring of their speech. This more responsive approach to speech style has as its basic premise the idea that speakers design and use their speech style while keeping their audiences throughout mind. The reason why it is important to consider the cultural aspects of speech style is that culture goes hand-in - hand with identity construction, which, in turn, is the result, among other linguistic and semiotic resources, of speech style" (Theodoropoulou, 2020).

Continuously, (Koussouhon \& Dossoumou, 2015) underlines "the act of competing for power through politic. Political, economic and social theories into motion, stated as the fight for translation power. Therefore, to this process language plays as the key role, for any political activity where also organized, accompanied, inspired and played by language. In extend language as the critical instruments that politicians use to influence the political thinking of both the electorate in order to acquire their ideologies to them. However, to reassure their followers of the legitimacy of their political arguments was the primary goal of politicians. Besides, derives from the use of tools that form the values and attitudes of others, was the subsequent of the political power legitimacy. At the top level, to such, an efforts to convince the electorate to discard their political ideologies and hold on to their own, was the reflection of a politicians. After all, as a speech linked either to the struggle for power or to the maintenance / control of power, it was the reflection of political speech. Again, the diverse of political speech, encompasses the different forms of speech made by politicians in the political forums. One of the famous political speeches is the victory speech of the President".

In fact, (Lacatus, 2020) proclaims "the social science scholars have been involved in the debate about the nature of populism and whether it is a form of political mobilization, a thin ideology, or a kind of discursive framework. Authoritarianism at its core is a type of political rhetoric based on the moral vilification of elites, who are seen as undemocratic and self-serving. Populism essentially proclaims the presence of an elite-induced crisis, aiming to challenge the existing order and giving the common will a voice. These storylines and personas are closely related to mainstream culture and an antiestablishment ethos in the context of the Trump campaign. Considered to be the passive mass, whose desires are dismissed in preference of arrogant economic leaders, corrupt legislators and minorities".

Added by (Krishna, 2020), therefore, "ethnic entity can be used to foster unity and increase marginalized communities, but it can also be used within a country to isolate other ethnic groups and establish strong divides. Conservatism is not in reality, liberalism's revolutionary philosophy, but rather its own isolated being; authors of 'new conservatism,' though were mainly concerned with the potential consequences of basically liberal transformations,' demonstrating this ideology in an inherently reactionary essence. Conservatism may be at the core of the mentality that may contribute to ethnic conflict, but populism is what drives it more a philosophy that insists that there are different factions in society: the' pure citizens' and the' corrupt class.' The separation of ethnic groups is triggered in many instances by a belief in the' populist extreme right,' a subset of right-wing populism that uses the ideology's Manichaean nature to explain nativism, a xenophobic type of nationalism".

(Kustov, A., \& Dai, 2020) argued, "has been increasingly seen in line with this reasoning, that some of the key roots of populism, such as antiimmigration feelings, are also resistant at the person level and resistant to different economic and demographic shocks. In addition, significant economic and political problems will endure not only these fundamental behaviors, but the human tendency for populism voting itself. But while populism's ideational literature rightly assumes that opportunistic politicians can exploit stable and widespread popular anti-immigration and anti-elitist sentiments strategically, there is very little 
explanation as to why populist rhetoric is relatively rare or why some actors use it more than others, even in the same electoral context. Unfortunately, populist intellectuals frequently define what games politicians currently play, what other political tactics are open, and why populist populism could nor may never be someone's best optimization answer".

In the perspective of democracy, as stated by (Themnér \& Sjöstedt, 2020) "the bond between stability as well as democracy are intricate. A strong link exists, on the one hand, between consolidated democracy and civil peace, where free and fair elections enable communities to settle collective conflicts more effectively. In the other hand, it has been suggested that democratization will have a negative impact on peace, since it encourages the potential of elites to play on nationalist feelings, which can spark ethnic conflict in reaction".

Moreover, to the rhethorics topic, I connected to the one scholar, and was said, "in the case of a potential U.S. In political interviews, comments, and tweets, President Donald Trump has regularly used the campaign slogan "extreme Islamic extremism." Islamophobia" refers to a deep distrust of the Islamic faith or Muslims, sometimes perceived as the geographical cause of extremist threats by one of them." Edward Said: Media attention also plays into cultural anxieties and raises, and it often involves the cultural misconception that there was some observable significance to information about the realities of Islam" (Brandt, 2020).

(Załęska, 2012) argues a speech in the context of rhetoric-politic based on modern rhetoricians, "speech analysts and linguists are focusing on the linguistic and metallurgical activity of speakers. Consequently, they seldom, if ever, answer the issue of what is politics according to any principled criterion, or which aspect of communicative operations relates to that concept and, thus, which part that omitted from the study. Rhetoric in politics, formulated as a means of thinking, was often typical of Aristotelian rhetoric of deliberation. Aristotle also theorized the linkage between politics and the rhetorical genre of deliberation, for example, in the manner along which decisions made within the available possibilities.

However, the deliberative genre concerns reasoned decision-making in general rather than exclusively 'power-infused/snatched encounters' involving 'socially competitive or unfair participants.' The word of "deliberative," was the way of thinking is not limited to political debate alone. It has a universal value, instead. Virtually any fair debate on any subject, including everyday social conduct, could occur. Even a politician can fairly be able to talk about the options and their viability (for the analysis of policy decisions). On the other hand, the political debate also could neglect this aspect, because of having qualified as political on the foundation of those two parameters". The criteria of source, added by (Załęska, 2012) can describe the rhetoric of political agents - leaders, candidates, parties - as political. Thus, the study of texts on subjects like power, democracy, justice, harmony, democratic institutions and so on is almost by necessity viewed as an analysis of "political rhetoric" and/or "political debate." Apart from topics historically labelled as political, although there issues that could be defined as political (politicization processes) or, inversely, no longer important to politics (DE-politicization processes).

In the other related study to speech in politic affair, speech discourse, also rhetoric-politic. (Kenski, Coe, \& Rains, 2020) debated from the other perspective, focused on incivility discourse. That scholar determined that Incivility in public debate has become a pressing issue for people and academics alike, but much study has centred narrowly on incivility in elite discourse. Finally, this study concluded from research findings, that different forms of incivility provide different replies. In fact, name-calling and vulgarity graded more uncivil than other speech acts. In addition, many socioeconomic, personality, and news intake factors evaluated as predictors of incivility attitudes.

(Jamieson, K. H., Volinsky, A., Weitz, I., \& Kenski, 2017) confirms, scholars accept that this is all and therefore difficult to provide for a wellestablished concept of civility, because communicative, rhetorical behaviour of civility and incivility, is situational and contestable. Therefore, for example, civility means an attitude of reverence, also of love, for our fellow citizens; respect for the dignity and a desire for the dignity of others; a form of collaboration; Incivility characterized as a degrading social face; that is, disdain for the values of the democratic group. As academics have moved to constructive perception, civility has become less likely to define in terms of the use of individual words or behaviour and is tendency used as mode of interaction and perception. In early modern England and Western Europe, the words civil and civility are increasingly [displac[ed] courteous and courtesy] as trendy terms denoting accepted behaviour. In the meantime, 'during the sixteenth century; the word of 'civility', the connotations of 'civilization' as the opposition between the 'civil' and the 'barbaric' inherent in classical literature was supposedly developed in reaction to the threat posed by the discovery of the 'savage inhabitants of the New World,' and then added to the distinction between the English civility and Irish".

Based on the preliminary studies above, my position on this paper was purely scaffold of scientific perspective. That intend to discuss about politic speech discourse, Language \& politic, also rhetoric language. Why I said like this, because the current president of France Republic, Macron, speech, influenced the significant chaos. In short, to my country, Indonesia, as the biggest Islam country 
in the world, we as the Indonesian felt so shock to listen to that speech of Macron, even in fact, myself is Catholic, was not agree to such approach that accumulated in politic speech. In the other hand, almost the news and politic discourse ended, as the news item and the consumption of every politician around the world, but in the contrary side to nonpolitic community, to Macron speech, just ended as controversy also come-up as a trigger or horizontal conflict [if that issue absolutely fail to solve], and I mean it. Therefore, as the part of language practices society, I believe, through this discussion, not only open our eyes of knowledge of speech as non-politic community, but also at the end, was possible to educate the reader to enrich the knowledge in broad area, such politic affair, but also developed our critical knowledge to react of political speech.

\section{METHOD}

My paper used an approach of document analyisis, that presented also discussed the certainty such as politic discourse also a politics speeches. In hence, to this practice of my paper flow, I scaffolded the sources of both primary sources and secondary parameter.

So that, to accelerate my research practice, I selected the sources of reading material through judgmental technique. Therefore, to the structure of materials explanation in analysis phase, esthabilished into three reading materials, that looked such as:

Table

Reading Materials

\begin{tabular}{|c|c|}
\hline Title & Topic \\
\hline $\begin{array}{l}\text { Critical Discourse Analysis } \\
\text { Analyzing the Beauty } \\
\text { Advertisement Discourse: } \\
\text { Dove's Campaign for Real } \\
\text { Beauty; }\end{array}$ & $\begin{array}{l}\text { Power and } \\
\text { Discourse: Access to } \\
\text { Discourse and Social } \\
\text { Struggle r } \\
\text { Mechanisms } \\
\text { achieve a } \\
\text { Society; } \\
\text { Ideology } \\
\text { Discourse: Ideology } \\
\text { in the Media \& The } \\
\text { Functional Model - a } \\
\text { Schemerrar } \\
\text { classifying language } \\
\text { structures. }\end{array}$ \\
\hline $\begin{array}{l}\text { Problems Related to the } \\
\text { Translation of Political } \\
\text { Texts }\end{array}$ & $\begin{array}{l}\text { - Political language } \\
\text { and translation; } \\
\text { The problem of } \\
\text { translating political } \\
\text { speeches }\end{array}$ \\
\hline $\begin{array}{l}\text { The Language of } \\
\text { Politics }\end{array}$ & $\begin{array}{l}\text { Making a speeches (p. } \\
35 \text { ) }\end{array}$ \\
\hline
\end{tabular}

\section{Power and Dsicourse}

(Hoepfner, 2007) stresses, "the discourse power as a tool of social practice was exercised to explain the relation within power and discourse inside a variety of contexts. The intensity behind debate describes how social behaviors that shape and form by power relations have been developed".

So, according to that scholar, a power, related to the the next topic of analysis about access to discourse and social struggle. Therefore, what exactly talked about; in Fairclough which takes the view of "cultural capital" by Pierre Bourdieu, which is metaphorically understood to be equivalent to economic capital. Access to and ownership of many cultural items may generate cultural capital, such as schooling, language use, access to and practice of exclusive social institutions, high employment respectively. Capital can be accrued. The dominant class group, the middle class and trades have more cultural wealth than the working class. The school system and other democratic structures were based on the system of social class affiliations. In the 'negative tremendous affect', like "Fairclough argues there is neither a "reduction in injustice" nor an "international conspiracy to hide control of manipulative purposes. The use of secret power was interpreted from him as a concession by ruling party.

In the issue of mechanisms to achieve a 'coherent society, explained that "a culture is formed, simplistically spoken through complex social behaviors and discourse forms. It needs to be consistent. Fairclough distinguishes three main types of mechanisms: 1. Naturalization, 2. Inculcation, and 3. Communication. The first mechanism describes social practices that are "universally followed and necessarily accepted because there seems to be no alternative, such as washing and caring for one's body every once in a while to stay healthy." The inculcation process can be used as the exercise of the purposes to "naturalize partial and interested activities to promote the exercise and preservation of control [and continuation of class dominance and division], secret control "behind" discourse. We might think of economic powerholders, to continue with our example from above, who want to naturalize the practice of everyday body care in order to regulate body activities and profit economically. The third approach to achieve commonality is the media system, "a method of reasoned communication and discourse that will for example, be an open debate on multiple public forums about physical welfare". So, absolutely, in a number of instances, speeches become psychologically constitutive. It is important to question who has access to discourses in order to grasp the political structures and tensions running behind discourses. Fairclough recommends reflecting in modern culture on processes of contact and inculcation, and their challenge".

\section{Ideology Discourse}

The notion of 'ideology' became a critical idea, and the following topics related to this notion, was 
first ideology in the media. "Critical linguistics notes that from an ideological point of view, texts have already been developed. In different modes of speech, values vary systematically. Furthermore the different usage of vocabulary to convey ideology with the implementation of the 'functional paradigm'. Then, in line of the functional model - a scheme for classifying linguistic structures, described about there were interrelated features in all of the languages performed: the ideal, the interpersonal and the textual function. His criticism of the model of Halliday is that it assumes that language use and contact are practiced separately and purposefully. In modern linguistics, thus, language would be seen as a practice or a method of action and that language is related to itself and to the situation or meaning".

\section{Politic Language and Translation}

The knowledge about this topic concerned to "the general characterization of political language that emphasized to the particular languages used in the social sciences belong to the field of political and diplomatic languages. Political language's nature and purpose are distinct from those of diplomatic language. And then, how did the context delivered to the the sub topic such as the political texts as specific expressions of the political language; if success is not obtained by persuasion based on argument, so manipulation, misinterpretations and fronting arise. This suggests that the speakers display fake evidence, exhibit false facts and make claims that can not be maintained due to objective conditions in order to accomplish their purpose. Regarding that tension, the following roles include political terminology: expressive function, which means that it communicates goals embedded in the actual politics circle; objective function, means that it has an objective cause for affecting people's thoughts, emotions, and therefore their actions; symbolic function, meaning that ideas and emotions are expressed through symbols in politics".

Moreover, in comparison, "substantial strategy consists of a revisable series of government decisions (example laws, contracts, taxation, etc.). It is essential to connect rhetorical politics and substantive policies to each other. Because og that, several assumptions provided to the analysis of rhetoric and substantive policies, for example, Politics has become a linguistic domain, mainly because of national conflicts. It occurs in a public space identified by the mass media; the advantages that are achievable in this struggle, such as connecting the good thoughts of one's own political party and bad ideas of one's own political group opponents may be turned immediately into electoral gains; the pre-formed political room would be the base for more political wars, in which the winners would be favored in the symbolic national battle. Those who are generally interested in the relationship between politics and people and the forms of communication that link these communities to each other in political communication. This theory distinguishes political expression, which is equivalent to all political acts, as a type of human activity. The use of language has an inherently instrumental aspect, the tool and object of the behavior being the language itself. It is clear that political negotiation research applies not only to linguistic devices or material problems, but also to methods used to gain a position of influence".

\section{The Problem of Translating Political Speeches}

As a matter of fact, to the problem of translating political speeches; as the language, "the political system is continuously undergoing a transition mechanism because it is a living thing, and that is why the status of both the language and the political system is immediate. That is why none of people are appropriate for analytical approaches. Political language cannot be treated as a compact technical language, although it has certain features of vocabulary. Political terms do not have an inherent meaning, they can only be described in relation to the rhetoric of which they are the components. In the other determines, may inferred, such as, an Efforts to describe terms such as political authority, the electoral structure or the system of controls and balances indicate that as specific words are doing these words do not have direct connections to the conceptual world. In the real world, there is nothing out there that can conceptually fit these political expressions; in the ordinary vocabulary, there is no identical phrase or name. Indeed, political terms should not be examined in isolation; the whole sentence and even the whole discourse must be taken into account in their analysis. If we want to examine everything, we need to do so in their context. We need to structure the latter in sentences".

In order to assist and bridged the knowledge of politic discourse, number of technique may taken a lead of grab the message of that discourse. "The 'translators' may use the following techniques in order to make culture specific elements and to represent a certain model of culture: misrepresentation: the removal or reduction of part of the text; extension: the development of explicit material that is implied in the original, either in the main body or in footnotes or in a glossary; strangeness: the replacement of slang stretches, dialect, nonsensical terms, et. Marked by italics or underlining); updating: replacement by digital equivalents of irrelevant or ambiguous information; situational analogy: implementation of a meaning which is more common than used in the original; creation: replacement of the source text more globally with a text that reflects only the original's basic message/ideas/functions". 


\section{The Language of Politic}

Making a speeches; "the art of persuasive debate is known as rhetoric. Students when arguing formally are encouraged to see falseness as entirely appropriate, given the rhetorical skills are strong enough. For example, debating teams are judged in contests on their verbal abilities, and their ability to speak persuasively, rather than the reliability of their opinions. Instead, successful prosecutors are also seen as someone who can convince a court to side on their case. Then judge on what really happened. The expectation will be that genuinely held opinions were presented, but if the audience is to both pay attention and be convinced, rhetorical abilities would be necessary. Politicians might argue which they want to bring forward proposals because they actually believe in, but others might argue that influencing the audience is the true aim. There is no easy solution to this question, since it is difficult to calculate values such as integrity and authenticity against any absolute criterion".

\section{RESULTS AND DISCUSSION}

Above of all analyses of related topic to how politics speeches remarked as the potential action to influence the other people that based on the aim of one of powerfull group or community needs. I underlined that politics speeches result, obviously, promoted the abstraction of idea and tricky to define in a simple way toward the 'communication, when an individual or community was just an ordinary people that stood-out of politics circle. In the other hand, politics speeches development, affected by number of factors such as 'the power of group or the entity of nation/government'. Besides that, the 'link of power', skills of communication, and the literacy of widespread issue. On the contrary, how hard for ordinary people, if responses to the communication of politics speeches, when grasp that message in 'isolate approach' without the awareness of politics issue. But, not yet, when seen from the nationalism perspective, as the citizen, it is a must to follow the obligation, either it was constructed from rhetorican approach, and the obligator only speak in abstraction, so it will unobvious when the listener unable to comprehend the message of obligation.

\section{CONCLUSION}

In my conclusion, probably thousands of cases in react of politic speech ended, only as 'media consumption', also the 'provocative' argument among politician. So it will deeply worst if such 'culture' repeatedly rise as the phenomenon that finally influence the negative impact such violence also criminal acts; also in crucial level will affect the sustainable life in wide spread. Therefore, I hope that for the future research will fulfill my scientific writing, that I believe the other scientific from politics, language or linguistic, also communication field, develop other comprehensive literacy that educated the society toward politic discourse and rhetoric issue.

\section{REFERENCES}

Abulof, Uriel. (2020). Taming self-determination: The trials of a political speech-act. International Political Science Review, 41(5), 622-637.

Aistrope, Tim. (2020). Popular culture, the body and world politics. European Journal of International Relations, 26(1), 163-186.

Ali, Inayat, \& Davis-Floyd, Robbie. (2020). The Interplay of Words and Politics During COVID19: Contextualizing the Universal Pandemic Vocabulary. Dear Readers.

Brandt, Stefan L. (2020). Fear of an Islamic Planet? Intermedial Exchange and the Rhetoric of Islamophobia. European Journal of American Studies, 15(3).

Hoepfner, Y. (2007). Critical Discourse Analysis Analyzing the Beauty Advertisement Discourse : Dove 's Campaign for Real Beauty. Www.Semanticscholar.org. Retrieved from

https://www.semanticscholar.org/paper/Critical -Discourse-Analysis-Analyzing-the-Beauty$\% 3 \mathrm{~A}$

Hoepfner/667442efccf6b5c9b4646219652c07 $7 \mathrm{~d} 0 \mathrm{e} 475016$

Jamieson, K. H., Volinsky, A., Weitz, I., \& Kenski, K. (2017). The Political Uses and Abuses of Civility and Incivility. In K. Kenski \& K. H. Jamieson (Eds.), Oxford Handbooks Online (Book Chapter). Oxford University Press.

Kenski, Kate, Coe, Kevin, \& Rains, Stephen A. (2020). Perceptions of uncivil discourse online: An examination of types and predictors. Communication Research, 47(6), 795-814.

Koussouhon, Leonard A., \& Dossoumou, Ashani M. (2015). Political and ideological commitments: A systemic functional linguistic and critical discourse analysis of president Buhari's inaugural speech. International Journal of Linguistics and Communication, 3(2), 24-34.

Krishna, Aishwari. (2020). How Populist Conservatism Influences the Rhetoric of Ethnic Entrepreneurs. Inquiries Journal: Special Editions, 2020(1). 
Kustov, A., \& Dai, Y. (2020). “When Do (and Don't) Politicians Use Populist Rhetoric? Populism as a (De)mobilization Gamble," Alexander Kustov, Yale Jackson Institute / Institution for Social and Policy Studies. Isps.Yale.Edu. Retrieved from https://isps.yale.edu/events/2019/12/when-doand-dont-politicians-use-populist-rhetoricpopulism-as-a-demobilization

Lacatus, Corina. (2020). Populism and President Trump's approach to foreign policy: An analysis of tweets and rally speeches. Politics, 0263395720935380.

Medriano Jr, Ramon S., \& De Vera, Presley V. (2020). Dominance Construction in Monologic
Political Discourse Based on Selected Public Speeches of President Rodrigo Roa Duterte. Online Submission.

Themnér, Anders, \& Sjöstedt, Roxanna. (2020). Buying Them Off or Scaring Them Straight: Explaining the Electoral Rhetoric of Warlord Democrats. Security Studies, 29(1).

Theodoropoulou, Irene. (2020). Speech style as political capital: Barack Obama's Athens speech. Journal of Multicultural Discourses, 15(3), 325-339.

Załęska, M. (2012). Rhetoric and Politics. In Rhetoric-Politics (pp. 1-30). Cambridge Scholars Publishing.

\section{Copyright holder:}

Thobias Sarbunan (2020)

First publication right :

Journal of Social Science

This article is licensed under:

(c) (i) (? 